\title{
The Narrow Ontic Counterfactual Account of Distinctively
}

\section{Mathematical Explanation}

\section{Mark Povich}

\begin{abstract}
An account of distinctively mathematical explanation (DME) should satisfy three desiderata: it should account for the modal import of some DMEs; it should distinguish uses of mathematics in explanation that are distinctively mathematical from those that are not (Baron [2016]); and it should also account for the directionality of DMEs (Craver and Povich [2017]). Baron's (forthcoming) deductive-mathematical account, because it is modeled on the deductivenomological account, is unlikely to satisfy these desiderata. I provide a counterfactual account of DME, the Narrow Ontic Counterfactual Account (NOCA), that can satisfy all three desiderata. NOCA appeals to ontic considerations to account for explanatory asymmetry and ground the relevant counterfactuals. NOCA provides a unification of the causal and the non-causal, the ontic and the modal, by identifying a common core that all explanations share and in virtue of which they are explanatory.

1 Introduction

2 Desiderata for an Account of Distinctively Mathematical Explanation

3 Baron's Deductive-Mathematical Account

4 The Narrow Ontic Counterfactual Account (NOCA)

5 Ontic Demystification

6 Objections to NOCA
\end{abstract}




\section{Conclusion}

\section{Introduction}

A simplistic and Whiggish history of the philosophy of scientific explanation, modelled after a terribly stripped-down reading of Salmon's ([1989]) Four Decades, might go as follows: in the beginning was Hempel, with whose covering law $(\mathrm{CL})$ model of explanation ${ }^{1}$ the main problems in the philosophy of explanation were thought, for the most part, to have been solved. There was peace in the land... for a while. Then came mumblings of discontent. For, most of the problems that faced the CL model resulted, many thought, from its inability to account for the central role of causation in scientific explanation. Mumblings magnified into roars and the $\mathrm{CL}$ model was burst asunder. A new account of scientific explanation - the causal-mechanical account (Salmon [1989]) - gained hegemony, and peace and consensus returned. In the last couple of decades, mumblings of discontent have started again to arise: equilibrium explanations, optimality explanations, renormalization group explanations, topological explanations. How can the causal hegemony in the philosophy of explanation account for all these $?^{2}$ The causal hegemony must give way to a new one, one that is either a more inclusive theory that covers both causal and non-causal explanation, or a principled explanatory pluralism according to which different kinds of explanation gain their explanatory force from ultimately different sources.

\footnotetext{
${ }^{1}$ Throughout, by 'explanation' I mean 'scientific explanation' and I will not try to distinguish this from other kinds of explanation (for example, [purely] mathematical, moral, or metaphysical explanation).

${ }^{2}$ See Skow ([2016]) for a valiant effort to maintain the causal hegemony in the face of these alleged counterexamples, though he does add that not only causing, but grounding, can be explanatory. Claims that all explanation is causal are rare - this is one way in which the story is simplistic - though claims approaching that can be found in Salmon ([1984]) and Lewis ([1986]).
} 
One of the strongest challenges to the causal-mechanical account of scientific explanation is so-called distinctively mathematical explanation (DME) (Baker [2005], [2012]; Colyvan [1998]; Lange [2013]; Leng [2005]; Mancosu [2008]; Steiner [1978]). Unlike causalmechanical explanations, DMEs do not gain their explanatory power from accurately describing the causes of, or the mechanism that constitutes, the explanandum phenomenon (that is, the phenomenon to be explained). Instead, according to Lange's ([2013]) account, on which I will focus in this paper, DMEs work by showing the natural ${ }^{3}$ explanandum to follow in part from a mathematical fact, a fact modally stronger than any fact about causes, mechanisms, and even natural laws ${ }^{4}$. In that sense, a DME shows that the explanandum had to happen, in a sense stronger than any ordinary causal law can supply.

More needs to be said about DMEs before we can confidently assess the true strength of their challenge to the causal consensus and to explanatory monism generally. In this paper, I begin to develop an account of DME that, while it challenges the causal consensus narrowly construed, paints causal-mechanical explanation and DME as species of a single ontic genus: both gain their explanatory power from ontically-backed counterfactual dependence. In Section 2, I present three desiderata that any account of DMEs should satisfy: the modal, distinctiveness, and directionality desiderata. In short, it should account for the modal import of some distinctively mathematical explanations, distinguish uses of mathematics in explanation

\footnotetext{
${ }^{3}$ I use 'natural fact' and 'empirical fact' synonymously, as distinguished from purely mathematical facts. For the purposes of this paper, I take the distinction to be relatively self-evident, but I touch on it again later when I discuss mixed natural-mathematical facts.

${ }^{4}$ Lange ([2013], p. 504) also includes under the umbrella of explanations by constraint (of which DMEs are a species) explanations that show the explanandum to follow from any fact, not just mathematical facts, modally stronger than natural law. Here, I limit myself to mathematical explanantia (that is, the facts that do the explaining), but see footnote 26 .
} 
that are distinctively mathematical from those that are not (Baron [2016]), and account for their directionality (Craver and Povich [2017]). In Section 3, I show how a recent proposal (Baron forthcoming) is unlikely to satisfy at least one of the desiderata, the directionality desideratum. In Section 4, I show how my counterfactualist account, the Narrow Ontic Counterfactual Account (NOCA), can satisfy all three desiderata. According to counterfactualism about explanation, the explanatory relation - the relation that holds between explanantia and explanandum - is a relation of counterfactual dependence. NOCA is a species of this kind of counterfactualism that makes use of a special narrowing procedure to satisfy the three desiderata. In Section 5, I gesture towards future work. For, although NOCA meets all the desiderata, it ultimately remains incomplete until the relation between mathematical facts and the natural facts that they explain, in virtue of which the latter counterfactually depend on the former, is demystified. In other words, this demystification challenge is the challenge of clarifying how natural facts can depend counterfactually only upon mathematical facts. In Section 6, I consider some objections to my account.

\section{Desiderata for an Account of Distinctively Mathematical Explanation}

To inspire a revolution against the causal hegemony and lay the foundations for a new consensus, a philosophical account of DME must be developed, a development to which the present work is a contribution. What should a philosophical account of DME do? There are at least three desiderata for such an account. Two come from Baron ${ }^{5}$ ([2016]), and the third comes from Craver and Povich ([2017]):

\footnotetext{
${ }^{5}$ Baron ([2016]; [forthcoming]) calls distinctively mathematical explanations 'extra-mathematical explanations'.
} 
The Modal Desideratum: an account of DME should accommodate and explicate the modal import of some DMEs.

The Distinctiveness Desideratum $^{6}:$ it should distinguish uses of mathematics in explanation that are distinctively mathematical from those that are not.

The Directionality Desideratum: it should accommodate the directionality of DME. ${ }^{7}$

The first desideratum any account of DME should satisfy is the modal desideratum. In some DMEs, the explanandum is not shown merely to have occurred, but to have occurred with a certain modal force - the explanandum had to occur or be the case ${ }^{8}$. This does not mean that the explananda of DMEs are themselves modal facts, though some can be (more on this at the end of Section 4). In other words, some DMEs show that the explanandum had to occur or be the case, with a modal strength proportional to the modal strength of the mathematical fact that explains it. This is the case even if the explanandum is not itself a modal fact (for example, necessarily, p). All the DMEs I consider here do possess a certain kind of necessity. Perhaps there are some DMEs whose explananda do not possess any kind of necessity. If so, then my account should be viewed as an account only of those DMEs that work by showing that the explanandum had to occur or be the case (but see footnote 8). My account is similarly

\footnotetext{
${ }^{6}$ Baron ([2016]) calls this the genuineness constraint.

${ }^{7}$ There may be good reasons to restrict this desideratum to non-modal explananda. I return to this issue below. This desideratum will come up again in slightly different form for my own account in Section 5.

${ }^{8}$ In his book, Lange ([2016], p. 131) writes that the explananda of DMEs need not be necessary. I find this hard to square with Lange's repeated claims in [2016] and [2013] that DMEs work by showing their explananda to be necessary (for example, [2013], pp. 485, 491; [2016], pp. 30, 37, 38). His 'type-(n)' and 'type-(c)' explanations by constraint (of which DMEs are a species) are somewhat analogous to my 'wide' and 'narrowed' explanations. (Type-( $\mathrm{m})$ DMEs explain modal facts. Modal explananda are addressed below.) I see two options here for my account: either 1 ) it is an account only of type-(c) and type-(m) DMEs; or 2) I add that a 'wide' explanation is a DME if and only if it can be turned into a 'narrowed' explanation that is a DME by shifting its empirical premise into the explanandum-statement. This has the consequence that the original flagpole case is a DME, but this is arguably the case on Lange's account too (he seems to agree that it is in his [forthcoming]), though getting into this would take me too far afield.
} 
restricted to explanations of natural facts in which the explanatory work is done entirely by mathematical facts and not by some combination of mathematical and natural facts. ${ }^{9}$

Let me present an example that, among others, will occur throughout the paper: Terry's trefoil knot (Lange [2013]) ${ }^{10}$. The explanandum in this example is the fact that Terry failed ${ }^{11}$ to untie his shoelace. The explanantia are the empirical fact that Terry has a trefoil knot in his shoelace and the mathematical fact that the trefoil knot is distinct from the unknot (a loop without knots), that is, the trefoil knot cannot be untied. As Lange ([2013]) notes, Terry's failure is modally robust. Terry did not fail because of any physical obstacle, limitation, or infelicity in the causal order. Terry had to fail, given that the knot was a trefoil knot. And this explains why he did fail. An account of DME needs to accommodate and explicate this modal import.

Any account of DME should distinguish uses of mathematics in explanation that are distinctively mathematical from those that are not (Baron [2016]). Call this the distinctiveness desideratum. Here, all we really have to go on is the contrast between are paradigm cases of DME and paradigm cases of non-DME that deploy mathematics but are not distinctively mathematical. The account should classify the paradigm DMEs as DMEs and the paradigm nonDMEs as non-DMEs. Terry's trefoil knot provides one paradigm DME. Another is the case of Königsberg's bridges (Lange [2013]). The explanandum in this case is the fact that Marta ${ }^{12}$ failed

\footnotetext{
${ }^{9}$ I thank an anonymous reviewer for suggesting this caveat.

${ }^{10}$ Baron's ([2016]; [forthcoming]) paradigm DME is the cicada case (see (Baron [2016]; [forthcoming]) and (Lange [2013]; [2016]) for details on the case). I chose to use different cases because they have fewer premises and are therefore easier to work with. The arguments in this paper apply equally to the cicada case; see footnote 23.

${ }^{11}$ The explanandum could be that Terry had to fail. For now, I stick to non-modal explananda. Modal explananda are considered at the end of Section 4.

12 Though this case and the previous come from Lange, the names 'Terry' and 'Marta' come from (Craver and Povich [2017]). This choice to make the explananda particular events should not affect the main points of this paper.
} 
to cross each of Königsberg's bridges exactly once (an Eulerian walk). The explanantia are the empirical fact that Königsberg's bridges form a network of four nodes (landmasses) - three nodes with three edges (bridges), one with five - and the mathematical fact that such a crossing (an Eulerian walk) is only possible in networks where either every node or every node but two is touched by an even number of edges. Another is the case of Patty's pendulum (Lange [2013]). The explanandum in this case is the fact that Patty's pendulum has at least four equilibrium configurations. The explanantia are the empirical fact that Patty's pendulum is a double pendulum and the mathematical fact that the double pendulum's configuration space is a torus with at least four stationary points.

As paradigm non-DMEs that nonetheless deploy mathematics, I will use Bromberger's ([1966]) flagpole and Baron's ([2016]) train case. In Bromberger's flagpole, the explanandum is the fact that the length of a flagpole's shadow is $I$. The explanantia are the empirical facts that the angle of elevation of the sun is $q$ and that the height of the flagpole is $h^{13}$ and the mathematical fact that $\tan q=h / l$. Here, it seems, the mathematics merely tracks the relevant causal structure and the explanandum does not possess the modal strength of a DME's explanandum - the length of the flagpole's shadow did not have to be I. Another such case is Baron's train. The explanandum is the fact that train T arrives at station $\mathrm{S}$ at 3:00 pm. The explanantia are the empirical facts that T left from station $S^{\prime}, 10$ kilometers away, at 2:00 pm, going $10 \mathrm{kph}$ and the mathematical fact that $10 / 10=1$. Again, the mathematics seems merely to track the relevant causal structure and the explanandum does not possess the modal

\footnotetext{
${ }^{13}$ And the flagpole and ground are straight and form a right angle, and that the system is Euclidean, etc.
} 
strength of a DME's - the train did not have to arrive at 3:00 pm. ${ }^{14}$ I follow Baron (2016;

forthcoming) in taking the intuitions behind these cases to be data that an account of DME

must accommodate.

Finally, an account of DME should not classify 'reversals' ${ }^{15}$ of DMEs as DMEs. Call this

the directionality desideratum. As Craver and Povich ([2017]) show, Terry's trefoil knot and

Königsberg's bridges can be reversed into arguments with similar form that are arguably not

explanations ${ }^{16}$. In reversed trefoil knot, the explanandum is the fact that Terry does not (or did

not ${ }^{17}$ ) have a trefoil knot in his shoelace. The explanantia are the empirical fact that Terry

untied his shoelace and the mathematical fact that the trefoil knot is distinct from the unknot.

Craver and Povich ([2017]) argue that if the forward case is a DME, so is this one. Similarly, the

explanandum in reversed Königsberg's bridges is the fact that Königsberg's bridges do not form

a network of four nodes - three nodes with three edges, one with five - and the explanantia

are the empirical fact that Marta crossed each of Königsberg's bridges exactly once and the

mathematical fact that such a crossing is only possible in networks where either every node or

every node but two is touched by an even number of edges. I agree with Craver and Povich

([2017]) that, while the putative explanantia in these two reversals provide (perhaps

\footnotetext{
${ }^{14}$ You might think this is false. Given the other facts, the train did have to arrive at 3:00 pm and the length of the flagpole's shadow did have to be I. I think there is something to this, but the reader should wait until I show how NOCA can satisfy the distinctiveness desideratum in Section 4.

${ }^{15}$ I use scare quotes because, as Craver and Povich recognize, the 'reversed' explanations are not exact reversals of their forward counterparts. Rather, the empirical premise and the explanandum statement are swapped and negated. Their point is that the basic form of the argument is the same as that in the forward case, and, so, also seems distinctively mathematical if the forward case is. Both the 'forward' and 'reversed' arguments show that their respective explananda had to happen. This is why Lange's account of DME does not satisfy the directionality desideratum. For simplicity, henceforth I'll drop the scare quotes.

${ }^{16}$ See Lange ([forthcoming]) for a response to Craver and Povich ([2017]) and Povich ([under review]) for a reply to Lange's response.

${ }^{17}$ Either tense works.
} 
indefeasible) evidence for their explananda, they do not explain their explananda. There is some sense in which the reversals explain, but it is not the sense that is the focus of the philosophy of scientific explanation. Rather than explaining $p$ (or why $p$ ), the reversals explain why one knows or is justified in believing that $\mathrm{p}$. For example, the trefoil knot reversal does not explain the fact that Terry does not have a trefoil knot in his shoelace or why Terry does not have a trefoil knot in his shoelace, though it gives (perhaps indefeasible) evidence for believing that Terry does not have a trefoil knot in his shoelace. The same for all the other reversals. They give quite good reasons to believe their conclusion, but they do not explain it. This distinction between explanation and evidence/justification is what Hempel ([1965]) had in mind with his distinction between reason-seeking and explanation-seeking why-questions. One of the biggest problems for the covering-law model was its erasure of this distinction with the explanationprediction symmetry thesis. Some of the most influential counterexamples to the covering-law model exploited this distinction (Salmon [1989]). For example, the falling barometer gives one good reason to believe a storm will occur, but it does not explain its occurrence. An account of DME, then, should exclude these reversals as DMEs.

\section{Baron's Deductive-Mathematical Account}

Baron ([forthcoming]) has argued that his deductive-mathematical (DM) account of DME can satisfy the modal and distinctiveness desiderata. He does not consider the directionality desideratum. My aim here is to express some skepticism about whether it satisfies the distinctiveness and directionality desiderata. I do not pretend to show that the DM account cannot satisfy these desiderata, for reasons I make clear below.

Baron's ([forthcoming]) DM account of DMEs is as follows: 
1. DMEs are sound arguments.

2. The conclusion of a DME is a proposition stating the physical phenomenon to be explained.

3. Among the premises of a DME there must be at least one mathematical claim.

4. If the mathematical claim were removed from the premises of an explanatory argument, then the argument would become invalid.

5. The proposition stating the physical phenomenon is 'essentially deducible' from the argument's premises.

6. Such arguments obey relevance logic. ${ }^{18}$

Claims 1-4 are self-explanatory. Claims 5 and 6 require some elaboration. 'Essential deducibility'

in claim 5 is defined as follows:

A non-mathematical claim $P$ is essentially deducible from a premise set $S$ that includes at least one mathematical sentence $M$ just when for an appropriate choice of expressive resources there is a sound derivation of $P$ from $S$ and either for the same choice of expressive resources there is no sound derivation of $\mathrm{P}$ from a premise set $\mathrm{S}^{*}$ that includes only physical sentence[s] or all sound derivations of $P$ from premise sets $S_{1} \ldots S_{n}$ each of which includes only physical sentences are worse than the mathematical derivation or for all appropriate choices of expressive resources the best derivations use M.

The basic idea is that an argument is a DME just when it is sound, one of its premises states a

mathematical fact, and the argument is better than any sound argument for the explanandum

that does not invoke a mathematical premise. 'Better,' for Baron (forthcoming), is meant to

track normative explanatory criteria like unity (or strength) and simplicity (more on these

presently). When ranking arguments overall, one must balance simplicity and unity. The

essential deducibility constraint is intended to make the DM account satisfy the distinctiveness

desideratum. For, claims 1-4 count all explanations that use mathematics as DMEs, and claim 5

is intended to fix this.

\footnotetext{
${ }^{18}$ Claims 1-4 constitute Baron's ([forthcoming]) 'basic DM theory'. 5 and 6 are additions meant to handle certain problems with 1-4; claim 5 was added to satisfy the distinctiveness desideratum and claim 6 was added to handle the irrelevance problems that face deductive-nomological accounts. I have replaced occurrences of 'extramathematical explanation' with 'DME' throughout.
} 
However, it is arguable whether claim 5 does the fix, because it is not clear that claims 1-5 exclude the train and flagpole cases as DMEs. Arguably, the train and flagpole arguments are better (that is, stronger and simpler) than any sound arguments for the same explananda that do not invoke the relevant mathematical premises, if there be any such arguments. By 'simplicity,' Baron (forthcoming) means the number of premises in an argument. Baron relativizes strength or unificatory power to a choice of expressive resources and basic predicates. This is because strength is a measure of the deductive consequences of a premise set, and what can be deduced from a premise set depends on expressive resources and basic predicates. The basic predicates are those in the mathematical and scientific vocabulary in which the argument is couched. So, for example, the basic predicates in a biological explanation that invokes number theory are biological and number-theoretic predicates. An argument, then, is stronger or more unifying than another, both of which employ the same basic predicates, when more conclusions can be deduced from its premises. If Baron's account is to exclude the train and flagpole arguments as DMEs, there must be arguments for those conclusions that do not invoke the relevant mathematical premises and are just as strong and simple as the arguments that do. Baron has not shown what those arguments are and, so, has not excluded the train and flagpole cases as DMEs.

Claim 6 requires that DMEs obey relevance logic. This is meant to handle irrelevance problems that have been long-known to afflict deductive-nomological accounts of explanation. Adding ' $2+2=4$ ' to the premises of any sound argument results in a second sound argument. The second argument counts as an explanation if the first one does, even if the fact that $2+2=4$ is irrelevant to the conclusion. Relevance logic requires the premises of an argument to be 
relevant to their conclusion (and the antecedents of conditionals relevant to their consequents). For Baron (forthcoming), premises are relevant to their conclusion just when all the information contained within the conclusion is contained within the premises and each premise contains some part of the information in the conclusion.

I have already expressed skepticism that Baron's DM account satisfies the distinctiveness desideratum. It seems to me not to satisfy the directionality desideratum either. The trefoil knot and 'reversed' trefoil knot cases can both be expressed as sound arguments (Craver and Povich [2017]) that adhere to the DM model. In argument form, the trefoil knot case can be expressed as:

1. Terry has a trefoil knot in his shoelace. (empirical premise)

2. Trefoil knots are distinct from unknots (that is, cannot be untied). (mathematical premise)

C. Terry failed to untie his shoelace.

and its reversal can be expressed as:

1. Terry untied his shoelace. (empirical premise)

2. Trefoil knots are distinct from unknots (that is, cannot be untied). (mathematical premise)

C. Terry does not (or did not) have a trefoil knot in his shoelace.

This reversal is a sound argument. It contains a mathematical premise without which it would not be valid. It contains no irrelevant premises. Thus, the reversal satisfies conditions 1-4 and 6 . What about 5 ? Is there a better (that is, stronger and simpler) (or not worse) argument for the fact that Terry does not (or did not) have a trefoil knot in his shoelace that does not 
invoke a mathematical premise? Certainly, there is a straightforward causal explanation of that fact that need not (let us assume) invoke any mathematical premises, but is that argument simpler and stronger? It is hard to see how it could be. It is overwhelmingly likely that any causal explanation of this explanandum will either invoke the same mathematical premise or have more than two premises, and, so, will be less simple. Baron needs to specify what exactly the argument for the reversed explanandum is that strikes a better balance of simplicity and strength, without mathematical premises, than the reversed argument given above, or else his DM account will incorrectly count it as a DME.

Perhaps the simpler and stronger non-mathematical argument goes something like this: 1. For any person $x$, if $x$ untied their shoelace, then $x$ does not have a trefoil knot in their shoelace.

2. Terry untied his shoelace.

C. Terry does not have a trefoil knot in his shoelace.

There are no mathematical premises, and the argument is just as short and even more unified, because it captures every person who unties their shoelaces successfully, not just Terry. ${ }^{19}$ However, if this is right, then Baron's account will incorrectly exclude the forward version of the trefoil knot case as a DME as well. For, consider the following argument:

1. For any person $x$, if $x$ has a trefoil knot in their shoelace, then $x$ will fail to untie it.

2. Terry has a trefoil knot in his shoelace.

C. Terry failed to untie his shoelace.

\footnotetext{
${ }^{19}$ Thanks to an anonymous referee for this example.
} 
There are no mathematical premises, and the argument is just as short and even more unified, because it captures every person who has a trefoil knot in their shoelace, not just Terry. Thus, the same reasoning used to exclude the 'reversal' excludes the forward trefoil knot case as well.

Thus, it is unclear, but doubtful, whether Baron's DM account can meet the distinctiveness and directionality desiderata.

\section{The Narrow Ontic Counterfactual Account (NOCA)}

I now present my account of DME. It is a counterfactual account of explanation, inspired by Woodward's ([2003]) interventionism. According to counterfactualism, all explanations - causal or non-causal - count as explanations in virtue of the fact that they allow one to answer whatif-things-had-been-different questions (w-question) about the explanandum phenomenon. In other words, all explanations exhibit relations of counterfactual dependence, regardless of whether that dependence has a causal basis (Povich [2018], Reutlinger [2016], Rice [2015], Saatsi and Pexton [2013], Strevens [2008]). X counterfactually depends on $y$ if, and only if, were $y$ the case, then $x$ would be the case and were $\sim y$ the case, then $\sim x$ would be the case (Lewis [1973], p. 563). If $x$ and $y$ are actually the case, then the first counterfactual is automatically true. It would be quite a victory for the counterfactualist if she can unify causal and DMEs under a single, monistic account of explanation. How, then, does the counterfactualist account for DMEs? Can the counterfactualist satisfy all three desiderata? I will argue that she can.

Baron ([2016]) argues that the counterfactualist cannot satisfy the distinctiveness desideratum. The counterfactualist, according to Baron, holds that an explanation is a DME when it shows a natural fact to depend counterfactually on a mathematical fact (see, for 
example, Reutlinger's ([2016]) counterfactualism ${ }^{20}$, which does not satisfy the distinctiveness desideratum for this reason). However, this does not distinguish the train and flagpole cases from the trefoil knot and Königsberg's bridges cases. In the train case, the explanandum depends counterfactually on the mathematical fact that $10 / 10=1$. Were $10 / 10=2$, then the train would have arrived at the station at 4:00 pm rather than 3:00 pm. In the flagpole case, the explanandum depends counterfactually on the mathematical fact that $\tan q=h / l$. Were $\tan q=$ $h / l^{2}$, then the length of the flagpole's shadow would have been the square root of $/$ rather than I. So, naïve counterfactualism mistakenly counts the train and flagpole cases as distinctively mathematical, violating the distinctiveness desideratum. ${ }^{21}$

To get around this problem, I suggest that the counterfactualist follow Lange ([2013]) in taking the explananda of DMEs to be of a special, narrow sort ${ }^{22}$. This feature of Lange's account is often overlooked ((Craver and Povich [2017]) is an exception), but it is crucial. To spell this out, consider the following example from Lange ([2013], p. 508): 'Why are all planetary orbits elliptical (approximately)? Because each planetary orbit is (approximately) the locus of points for which the sum of the distances from two fixed points is a constant, and that locus is (as a matter of mathematical fact) an ellipse'. Lange argues that this is not a DME, and his reasons why are telling. According to Lange, this is not a DME because 'the first fact to which it appeals is neither modally more necessary than ordinary causal laws nor understood in the why question's context to be constitutive of being a planetary orbit (the physical arrangement in

\footnotetext{
${ }^{20}$ Reutlinger's ([2017]) counterfactualism also denies the directionality desideratum for non-causal explanations. ${ }^{21}$ This depends on the non-triviality of counterfactuals with impossible antecedents, which is controversial (Lewis [1973]). See (Baron, Colyvan, and Ripley [2017]) for a defense of non-triviality. I take non-triviality for granted throughout this paper.

${ }^{22}$ What was said in footnote 8 about the possibility that not all the explananda of DMEs are necessary also implies that perhaps not all are 'narrow'.
} 
question)' ([2013], p. 508). What this means is easier to understand if we consider Königsberg's bridges.

How exactly does the Königsberg's bridges case, which is a DME, differ from the elliptical orbits case that Lange says is not a DME? Both use empirical and mathematical premises to derive (a description of) a natural fact. The difference, according to Lange, is that, in the latter, having a certain structure (that is, [approximately] being the locus of points for which the sum of the distances from two fixed points is a constant) is not understood in the why-question's context to be constitutive of being a planetary orbit. In the former, having a certain structure (that is, being a network of four nodes; three nodes having three edges; one having five) is understood in the why-question's context to be constitutive of Königsberg's bridges. In an important sense, the empirical facts in the Königsberg's bridges case are metaphysically implicit in the explanandum, since they are partly constitutive of the physical task or arrangement at issue in the explanandum. To make this explicit, you could shift these empirical premises into the explanandum-statement: the special, narrower explanandum is the fact that no one has crossed each of Königsberg's bridges, which form a network of four nodes (landmasses), three nodes having three edges (bridges), one having five, exactly once ${ }^{23}$. Similarly, Lange takes it that being a trefoil knot is understood in the why-question's context to

\footnotetext{
${ }^{23}$ Lange makes this narrowing move explicitly when he considers the cicada case, which I mentioned in footnote 10. He argues that, for the cicada case to be a DME, the explanandum must not be that cicada life-cycle periods are prime rather than composite numbers of years ([2013], p. 498-9), which is what the explanandum is usually taken to be (for example, Baker [2005], [2009], [2012]; Baron [2016]; Lyon [2012]). To make this a DME, 'we narrow the explanandum to the fact that in connection with predators having periodic life-cycles, cicadas with prime periods tend to suffer less from predation than cicadas with composite periods do' ([2013], p. 499). This narrowed explanandum is the usual cicada explanandum, with that explanation's empirical explanans shifted into it. The reversed, narrowed explanandum would be the fact that some population of cicadas, which does not tend to suffer less from predation by predators with periodic life-cycles than other populations (that is, whose life-cycle period does not minimize intersection with predators' periods), does not have a prime life-cycle period.
} 
be constitutive of the knot in Terry's shoelace. Rather than taking the fact that Terry has a trefoil knot in his shoelace to be an empirical premise, that fact is presupposed in the properly narrowed explanandum, the fact that Terry failed to untie the trefoil knot in his shoelace. This is the 'narrow' to which is referred in the Narrow Ontic Counterfactual Account (NOCA) of DME. (What 'ontic' refers to will become clear in the next section.)

Understanding this narrow construal of the explananda of DMEs allows us to see why Lange's famous strawberry example is a DME, too, even though it seems prima facie exactly like the train or flagpole case. The explanandum in the strawberry case is the fact that mom failed to divide evenly her strawberries among her children. The explanantia are the empirical facts that she has twenty-three strawberries and three children, and the mathematical fact that twenty-three is not divisible by three. This would be like the train case, were it not for the fact that Lange takes it as constitutive of the physical task at issue that mom has twenty-three strawberries and three children. Therefore, in an important sense, the empirical premises do not function explanatorily like premises, and the explanandum could be stated more narrowly as the fact that mom failed to divide her twenty-three strawberries evenly among her three children. This explanandum includes in it the empirical facts that were taken as premises before (that is, that she has twenty-three strawberries and three children - obviously, the whyquestion's context also presupposes that Mary exists and attempts to make such a division). NOCA thus provides a solution for the counterfactualist: an explanation is a DME just in case it shows a natural ${ }^{24}$ fact to depend counterfactually only on a mathematical fact ${ }^{25}$. This

\footnotetext{
${ }^{24}$ Or a mixed natural-mathematical fact - see the discussion of this below.

${ }^{25}$ NOCA claims that in DME there is counterfactual dependence of a natural fact on a mathematical one. Thus, the truth of 'asymmetric counterfactuals' like 'had Patty's double pendulum not had at least four equilibrium
} 
satisfies the distinctiveness desideratum by counting the trefoil knot, Königsberg's bridges, and strawberries cases, properly narrowed, as DMEs, and by not counting the train, flagpole, and elliptical orbit cases as DMEs. (According to NOCA, the original 'wide' or 'unnarrowed' versions of the trefoil knot, Königsberg's bridges, and strawberries cases are not DMEs, but this is consistent with what Lange ([2013]) says on this issue. Of course, according to NOCA, properly narrowed versions of the train and flagpole cases are DMEs. But this is also consistent with Lange ([forthcoming]). $)^{26}$

This formulation of NOCA is but a promising first pass. We will see presently, when we consider just how the relevant counterfactuals are evaluated, that NOCA should say that an explanation is a DME just in case it shows a natural fact (weakly) necessarily to depend counterfactually only on a mathematical fact. We will also need to add a further necessitation condition to cover certain kinds of explanandum. This will all be explained in due course.

The same move of narrowing the explanandum also allows NOCA to satisfy the modal desideratum. Since the properly narrowed explanandum counterfactually depends only on a mathematical fact, changes in any empirical fact have no effect on the explanandum.

Can NOCA satisfy the directionality desideratum? As Craver and Povich ([2017]) show, both forward and reversed explananda follow ${ }^{27}$ from mathematical facts. However, this does

configurations, then a double pendulum's configuration space would not be a torus with at least four stationary points' does not pose a problem. They are already not DMEs according to NOCA. Furthermore, in asymmetric counterfactuals, the explanandum-fact is not an instantiation of the explanandum-fact (see Section 5).

${ }^{26}$ In footnote 4, I mentioned that Lange includes under the umbrella of explanations by constraint any explanation whose explanans is modally stronger than its explanandum and ordinary natural law, thereby constraining it. I expect that NOCA can accommodate these as well. For example, when a natural explanandum is shown weakly necessarily to depend counterfactually only on some law that is modally stronger than any ordinary law, such as a symmetry principle, conservation law, or coordinate transformation law, then you have one of these 'super-nomic' versions of DME (Lange [2013], p. 504). I cannot consider this further here though.

${ }^{27}$ Since 'following' is strictly a relation between propositions, descriptions of both forward and reversed explananda follow from a description of the mathematical fact. For simplicity, I avoid this way of talking. 
not imply that both forward and reversed explananda counterfactually depend on mathematical facts. To see this, let us focus on the trefoil knot case first. For now, I focus on the non-modal forms of these explananda - explananda whose descriptions do not include any modal terms. I return to explicitly modal explananda later.

Forward explanandum: Terry did not untie his shoelace that contains a trefoil knot. (Remember, we are only concerned with the narrowed explanandum that presupposes that Terry's shoelace contains a trefoil knot, because only by narrowing the explanandum can we satisfy the distinctiveness desideratum.)

Reversed explanandum: Terry does not have a trefoil knot in the shoelace that he untied. (Again, we are concerned only with the narrowed explanandum that presupposes that Terry untied his shoelace. $)^{28}$

Notice that both forward and reversed explananda follow from the relevant mathematical fact that the trefoil knot is distinct from the unknot (so, cannot be untied). The fact that both explananda follow from the mathematical fact shows again that an account according to which DMEs are arguments, and the explanatory relation of DMEs is entailment, like Baron's deductive-mathematical account, cannot satisfy the directionality desideratum (Craver and Povich [2017]).

However, NOCA gives the correct verdict on whether these explananda have DMEs. That is, NOCA correctly classifies the forward explanandum as having a DME and the reversed

\footnotetext{
${ }^{28}$ In what follows, I will omit the qualifier 'narrowed' when it is clear that it is the narrowed explanandum I have in mind.
} 
explanandum as not having one. Seeing why takes some work. First, consider the following two counterpossible counterfactuals ${ }^{29}$ :

$\mathrm{CP} 1$ : Were the trefoil knot isotopic to the unknot, Terry would have untied his shoelace that contains a trefoil knot.

CP2: Were the trefoil knot isotopic to the unknot, Terry would have had a trefoil knot in the shoelace that he untied.

These counterpossibles should be evaluated similarly to ordinary counterfactuals (Lewis [1973]; see (Baron, Colyvan, and Ripley [2017]) for a framework for evaluating counterpossibles). When evaluated at a world, we consider the nearest (that is, most similar) worlds where the antecedent is true and consider whether the consequent is true (Lewis [1973]). Thus, the truth or falsity of these counterpossibles depends entirely on the world at which they are evaluated. It turns out that any truth-value can be assigned to each of these counterpossibles in the appropriate world.

There are worlds where CP1 is true. For example, suppose Terry bends down to untie the trefoil in his shoelace. He tries in vain for seven hours before declaring it a lost cause. In this world, it is plausible that, were the trefoil knot isotopic to the unknot, Terry would have untied his shoelace that contains a trefoil knot since, in the worlds nearest to this one, where the trefoil knot is isotopic to the unknot, Terry does untie the trefoil knot in his shoelace.

There are worlds where CP1 is false. For example, suppose Terry bends down and is about to begin his attempt at untying the trefoil knot in his shoelace when he is hit by a bus. Here, it is plausibly false that, were the trefoil knot isotopic to the unknot, Terry would have

\footnotetext{
${ }^{29}$ I thank an anonymous reviewer for pressing me to clarify the evaluation of these counterpossibles.
} 
untied the trefoil knot in his shoelace. In the worlds nearest to this one, where the trefoil knot is isotopic to the unknot, Terry is hit by a bus before he can untie the trefoil knot in his shoelace.

There are worlds where CP2 is false. For example, suppose Terry comes home from work, unties the Thistlethwaite knot (which is isotopic to the unknot) in his shoelace, and makes dinner. In this world, it is plausibly false that, were the trefoil knot isotopic to the unknot, Terry would have had a trefoil knot in the shoelace that he untied. In the worlds nearest to this one, where the trefoil knot is isotopic to the unknot, Terry still has a Thistlethwaite knot in the shoelace that he untied.

There are worlds where CP2 is true. For example, suppose that Terry has a Thistlethwaite knot in his shoelace. Suppose further that Terry always gets shoelaces with his favorite untieable knot tied in them. His favorite untieable knot is the Thistlethwaite knot, though his favorite knot simpliciter is the trefoil knot; it beats out even the Thistlethwaite overall. Terry comes home from work, unties the Thistlethwaite knot in his shoelace, and makes dinner. In this world, it is plausible that, were the trefoil knot isotopic to the unknot, Terry would have had a trefoil knot in the shoelace that he untied. This is because, in the worlds nearest to this one, where the trefoil knot is isotopic to the unknot, the trefoil knot is Terry's favorite untieable knot, and he gets shoelaces with a trefoil knot tied in them. When he comes home from work, he unties the trefoil knot in his shoelace and makes dinner.

At this moment, first-pass-NOCA, according to which an explanation is a DME just in case it shows a natural fact to depend counterfactually only on a mathematical fact, seems out of luck. It says there are worlds where the forward explanandum has no DME, and there are 
worlds where the reversed explanandum has a DME, violating the directionality desideratum. ${ }^{30}$

Thus, first-pass-NOCA needs to be amended.

To see how NOCA should be amended, notice that the three DMEs we have considered so far have different kinds of explananda. The explananda of Königsberg's bridges and Terry's trefoil knot are 'action-oriented' - these explananda are facts about someone's failing to do something (that is, cross bridges and untie a knot). However, the explanandum in the case of Patty's pendulum is not like this - the explanandum is the fact that a certain object has a certain property (that is, that a certain pendulum has at least four equilibrium configurations). Perhaps the former kind of explanandum is an event and the latter kind is a state of affairs their exact nature does not matter for our purposes, though these are the terms ('event' and 'state of affairs') I will use to mark the distinction ${ }^{31}$. What matters is that they are different, and this gives us a clue about how to amend NOCA.

Let us see what happens if we make the explanandum in the case of Terry's trefoil knot a state of affairs instead of an event. Let us make the explanandum the fact that the knot in Terry's shoelace is distinct from the unknot. The explanantia are the same: the empirical fact that Terry has a trefoil knot in his shoelace and the mathematical fact that the trefoil knot is distinct from the unknot. This case fits Lange's ([2013]) criteria for DME: the explanantia are

\footnotetext{
${ }^{30}$ Of course, one could still defend first-pass-NOCA by arguing that 1 ) it is fine to say that the forward explanandum has no DME in cases like the one I presented, perhaps with the caveat that Terry's failure would have been distinctively mathematically explained, had he not been hit by a bus, and 2) it is incorrect that the reversed explanandum has a DME in cases like the one I presented, perhaps because a proper account of nearness of worlds, which determines what we hold fixed in counterpossible reasoning, would show that, in the nearest worlds, Terry still would not have had a trefoil knot in the shoelace he untied. This defense does not seem that unreasonable, but I will not make it here. (Note that the caveat in the first point seems to provide a way accepting that there is a DME in the bus case: simply say that an explanandum has a DME if and only if it counterfactually depends only on a mathematical fact or would counterfactually depend only on a mathematical fact.) ${ }^{31}$ I cannot here give an account of events or states of affairs or actions and each of their individuation conditions.
} 
either modally strong facts, such as mathematical facts, or understood in the why question's context to be constitutive of the physical arrangement or task at issue. If the original, event version of this case is a DME, then so is this state of affairs version. Presupposing the empirical fact creates the narrowed explanandum: the fact that the trefoil knot in Terry's shoelace is distinct from the unknot.

The 'reversal' of the state of affairs version of Terry's trefoil knot is as follows. The explanandum is the fact that Terry does not have a trefoil knot in his shoelace. The explanantia are the empirical fact that the knot in Terry's shoelace is isotopic to the unknot and the mathematical fact that the trefoil knot is distinct from the unknot. Presupposing the empirical fact creates the narrowed explanandum: the fact that the knot in Terry's shoelace, which is isotopic to the unknot, is not a trefoil knot. Or, put more simply, that Terry does not have a trefoil knot in his untieable shoelace.

Now consider these counterpossibles:

CP1': Were the trefoil knot isotopic to the unknot, the trefoil knot in Terry's shoelace would have been isotopic to the unknot.

CP2': Were the trefoil knot isotopic to the unknot, Terry would have had a trefoil knot in his untieable shoelace.

Unlike CP1, CP1' is (weakly) necessarily true. By that I mean that any world where the explanandum exists (that is, any world where the trefoil knot in Terry's shoelace is distinct from the unknot) is a world where $C P 1^{\prime}$ is true. (CP1' is arguably false in, for example, empty worlds.) CP2', however, is not (weakly) necessarily true. Our counterexample to CP2 above is also a counterexample to CP2'. Thus, this suggests that NOCA should be amended to say that an 
explanation is a DME just in case it shows a natural fact (weakly) necessarily to depend counterfactually only on a mathematical fact - it shows that every world where the explanandum exists is a world where it counterfactually depends only on a mathematical fact. NOCA thus correctly says that the forward explanandum has a DME and the reversed explanandum does not.

This is all well and good, but what about the event version of Terry's trefoil knot with which we started? My proposal is that the forward, but not the reversed, explananda of the state of affairs version and the event version are related by a componency and necessitation relation. All four explananda are as follows:

Forward Event (FE): Terry did not untie the trefoil knot in his shoelace.

Reversed Event (RE): Terry does not have a trefoil knot in the shoelace he untied. Forward State of Affairs (FSA): The trefoil knot in Terry's shoelace is distinct from the unknot.

Reversed State of Affairs (RSA): Terry does not have a trefoil knot in his untieable shoelace.

We have seen that FSA weakly necessarily counterfactually depends only on a mathematical fact; thus, according to NOCA, it has a DME. RE and RSA do not, as shown by the counterexamples to $\mathrm{CP} 2$ and $\mathrm{CP}^{\prime}$. Furthermore, FSA necessitates FE: every world in which FSA is true is a world in which FE is true ${ }^{32}$. However, FSA does not necessitate RSA (or RE): not every world in which FSA is true is a world in which RSA (or RE) is true. According to FSA, Terry has a

\footnotetext{
32 Note three things about necessitation. First, the necessitation relation (of a given modal strength) is transitive: if $x$ necessitates $y$ and $y$ necessitates $z$, then $x$ necessitates $z$. Second, $x$ makes impossible $y$ iff $x$ necessitates $\sim y$. Third, 'every $x$-world is a y-world' is logically equivalent to 'no world is an $x$-world and not a y-world'.
} 
trefoil knot in his shoelace; according to RSA (or RE), he does not have a trefoil knot in his shoelace. Thus, FSA and RSA (or RE) cannot both be true (without contradiction) in the same worlds. We could continue examining whether further necessitation relations hold between any of these explananda, but this is all I need to complete NOCA. NOCA says that FSA has a DME, and we want it to say that FE does too, but that RSA and RE do not. Thus, we amend NOCA to say that an explanation is a DME just in case either a) it shows a natural fact weakly necessarily to depend counterfactually only on a mathematical fact, or b) it shows a natural event to be necessitated by a component natural fact that weakly necessarily counterfactually depends only on a mathematical fact. FSA meets condition a). FE meets condition b) since it is necessitated by FSA and FSA is a component of the event FE ${ }^{33}$. RE and RSA meet neither condition. Thus, NOCA gives the right verdicts.

Let me go through another example of DME to allay the worry that the previous result is an artifact of that case specifically. Consider Königsberg's bridges again. The narrowed explananda are as follows:

\footnotetext{
33 By 'component natural fact' I mean that the same object and property that constitute the natural fact are constituents of the natural event. As a reviewer points out, a purely modal notion like necessitation leaves the account open to counterexamples, because the necessitation relation also holds between FSA and any (strongly) necessary natural events (see (Schaffer [2010])). Thus, the appeal to componency is meant to capture the metaphysically intimate relation between FSA and FE. This is another place in my account where the ontic (namely, a componency relation) plays a role, more on which below. The reviewer also notes that one way of avoiding the previously mentioned counterexamples is to give an account of natural events on which (strongly) necessary events are not natural. This may work, but I will not pursue that suggestion here. Even if I pursue the componency strategy, the reviewer is correct that more needs to be said about natural events. For, the componency strategy seems to require that natural events be natural in a sense (perhaps along the lines of (Lewis [1983])) that excludes conjunctive events. For example, the conjunctive event - if that's what it is - composed of FE and the fact that water is $\mathrm{H}_{2} \mathrm{O}$ is arguably necessitated by FSA and FSA is a component of it. Such conjunctive events need to be excluded as unnatural. Or perhaps we could say that the necessitation in question is logical, so that FE conjoined with the fact that water is $\mathrm{H}_{2} \mathrm{O}$ is not logically necessitated by FSA - there are logically possible worlds where FSA and $\mathrm{FE}$ are true, but water is $\mathrm{XYZ}$.
} 
Forward explanandum (FE'): Marta failed an Eulerian walk across Königsberg's bridges (which we presuppose form a network of four nodes, three of which have three edges and one of which has five ${ }^{34}-$ call this network structure $\left.\mathrm{P}\right)$.

Reversed explanandum (RE'): Königsberg's bridges, across which Marta made an Eulerian walk, do not have network structure P. (In this narrowed explanandum, the empirical premise that Marta made an Eulerian walk across the bridges is presupposed; we do not, obviously, presuppose that Königsberg's bridges have network structure P.) Notice, again, that both forward and reversed explananda follow from the relevant mathematical fact that an Eulerian walk cannot be made across a network with a certain topology: that Marta failed follows from the fact that Eulerian walks are only possible on some network topologies and that the bridges across which Marta made an Eulerian walk do not have a certain network topology follows from the fact that Eulerian walks are only possible on some network topologies.

Now consider the following two counterpossible counterfactuals:

CP3: Had network structure P permitted an Eulerian walk, Marta would have made an Eulerian walk across Königsberg's bridges (which we presuppose have network structure P).

CP4: Had network structure P permitted an Eulerian walk, Königsberg's bridges (which, here, we do not presuppose have network structure P), across which Marta made an Eulerian walk, would have had network structure P.

\footnotetext{
${ }^{34}$ Königsberg's bridges no longer have that topology.
} 
As with $\mathrm{CP} 1$ and $\mathrm{CP} 2, \mathrm{CP} 3$ and $\mathrm{CP} 4$ have different truth values in different worlds. We can construct such worlds on analogy with the worlds we constructed for CP1 and CP2. Thus, for example, CP3 is false at a world where Marta is hit by a bus before completing her walk, so first-pass NOCA says that case has no DME. Similarly, CP4 is true at a world where Marta builds her favorite Eulerian bridges and makes Eulerian walks across them. Her favorite bridges have network structure $\mathrm{P}$, but, unfortunately, those do not permit Eulerian walks. However, had network structure P permitted an Eulerian walk, Marta would have built it and made an Eulerian walk across it.

The same strategy of converting event explananda to state of affairs explananda works here. Thus, the state of affairs version of Königsberg's bridges is as follows. The explanandum in this case is the fact that Königsberg's bridges do not permit an Eulerian walk. The explanantia are the same as before: the empirical fact that Königsberg's bridges have network structure $\mathrm{P}$ and the mathematical fact that network structure P does not permit an Eulerian walk. The narrowed explanandum is the fact that Königsberg's bridges, which have network structure $\mathrm{P}$, do not permit an Eulerian walk (FSA').

The reversal of the state of affairs version is this. The explanandum in this case is the fact that Königsberg's bridges do not have network structure P. The explanantia are the empirical fact that Königsberg's bridges permit an Eulerian walk and the mathematical fact that an Eulerian walk is not permitted on network structure $P$. The narrowed explanandum is the fact that Königsberg's bridges, which permit an Eulerian walk, do not have network structure $\mathrm{P}$ $\left(\right.$ RSA $\left.^{\prime}\right)$.

Now consider these counterpossibles: 
CP3': Had network structure P permitted an Eulerian walk, Königsberg's bridges, which have network structure $\mathrm{P}$, would have permitted an Eulerian walk.

CP4': Had network structure P permitted an Eulerian walk, Königsberg's bridges, which permit an Eulerian walk, would have had network structure P.

Unlike CP3, CP3' is weakly necessarily true - any world where Königsberg's bridges do not permit an Eulerian walk is a world where CP3' is true. CP4', however, is not weakly necessarily true. Thus, according to NOCA, the explanandum in the forward state of affairs version (FSA') of Königsberg's bridges has a DME, but the explanandum in the reversed state of affairs version (RSA') of Königsberg's bridges does not. Furthermore, FSA' necessitates the original forward event explanandum (FE') but not the original reversed event explanandum (RE') or RSA'. Thus, FSA' meets condition a) of NOCA, FE' meets condition b), and RSA' and RE' meet neither.

The reasoning through which I have gone in the previous examples can be straightforwardly extended to the cases of Mary's strawberries and Patty's pendulum ${ }^{35}$ (Lange [2013]; Craver and Povich [2017]). I will not repeat the reasoning, but the relevant counterpossible counterfactuals are:

CP5: Had twenty-three been divisible by three, then Mary would not have failed to divide her twenty-three strawberries evenly among her three children.

CP6: Had twenty-three been divisible by three, then Mary, who evenly divided her strawberries among her children, would have had twenty-three strawberries and three children.

\footnotetext{
${ }^{35}$ Note that Patty's pendulum already has a state of affairs explanandum. It thus meets condition a) of NOCA. One could construct an event version of Patty's pendulum whose explanandum is the fact that Patty fails to do something that is made impossible by the setup. This explanandum would meet condition b) of NOCA.
} 
CP7: Were a double pendulum's configuration space not a torus with at least four stationary points, then Patty's double pendulum would not have had at least four equilibrium configurations.

CP8: Were a double pendulum's configuration space not a torus with at least four stationary points, then Patty's pendulum, which does not have at least four equilibrium configurations, would have been a double pendulum.

In each case, the narrowed, forward explanandum, but not the narrowed, reversed explanandum, either weakly necessarily depends counterfactually on the relevant mathematical fact or is necessitated by a fact that weakly necessarily depends counterfactually on the relevant mathematical fact. Can we expect this always to be the case? I think so. In each case, the counterpossible that has a narrowed, forward explanandum statement as its consequent (that is, CP 1, CP 3, CP 5, and CP 7) is doing something akin to modus ponens, and the counterpossible that has a narrowed, reversed explanandum statement as its consequent (that is, CP 2, CP 4, CP 6, and CP 8) is doing something akin to affirming the consequent. This is due to the fact that Craver and Povich ([2017]) construct their reversals by swapping and negating the empirical premise and explanandum statement of a forward DME.

Earlier I said that I would treat modal explananda separately, which I do now. First, let me make clear the difference between non-modal and modal explananda. Recall the forward and reversed explananda in the event version of Terry's trefoil knot:

FE: Terry did not untie his shoelace that contains a trefoil knot.

RE: Terry does not have a trefoil knot in the shoelace that he untied. 
I call these non-modal explananda because no modal terms appear in their description. The modal desideratum applies just as much, if not principally, to these non-modal explananda, since they are natural facts that possess a kind of necessity ${ }^{36}$ even though they are not facts about necessity. The following are their modal counterparts:

Forward explanandum ${ }^{\mathrm{M}}\left(\mathrm{FE}^{\mathrm{M}}\right)$ : Terry could not have untied his shoelace that contains a trefoil knot.

Reversed explanandum ${ }^{\mathrm{M}}\left(\mathrm{RE}^{\mathrm{M}}\right)$ : Terry could not have a trefoil knot in the shoelace that he untied.

Now, according to NOCA, an explanandum has a DME just in case a) it weakly necessarily counterfactually depends only on a mathematical fact or b) it is necessitated by a natural fact that weakly necessarily counterfactually depends only on a mathematical fact. Thus, consider the following two counterpossibles:

$\mathrm{CP} 1^{\mathrm{M}}$ : Were the trefoil knot isotopic to the unknot, Terry could have untied his shoelace that has a trefoil knot.

$\mathrm{CP}^{\mathrm{M}}{ }^{\mathrm{M}}$ : Were the trefoil knot isotopic to the unknot, Terry could have had a trefoil knot in the shoelace that he untied.

\footnotetext{
${ }^{36}$ These explananda possess a kind of weak necessity (Kripke [1971]) - truth in all possible worlds in which the individuals exist. It is arguably false that strongly necessarily Mary failed to divide evenly her 23 strawberries among her three children, because that fact does not obtain in worlds where Mary does not exist. It also arguably does not obtain in worlds where she exists but does not attempt such a division. But every world where she exists and attempts such a division is a world where she fails. 'Necessarily, Mary did not divide her 23 strawberries evenly among her three children' gets around this, since this is arguably true in worlds where Mary exists and does not attempt such a division. I do not take this to imply that no explananda of DMEs are strongly necessary though. Weakly necessary truths can be turned into strongly necessary ones by conditionalization. The following might be an explanandum that admits of DME and is strongly necessary: if Mary tries to divide her 23 strawberries evenly among her three children, she will fail. I cannot consider this further here though.
} 
There are worlds where $\mathrm{CP} 1^{\mathrm{M}}$ is false. For example, suppose that the only possible way for Terry to get access to the trefoil knot in his shoelace requires that Terry untie a figure eight knot, which is also distinct from the unknot. In this scenario, the fact that Terry could not have untied his shoelace that contains a trefoil knot does not counterfactually depend on the fact that the trefoil knot is distinct from the unknot: were the trefoil knot isotopic to the unknot, it still would have been impossible for Terry to have untied his shoelace that has a trefoil knot, since he would first have to have untied a figure eight knot.

There are worlds where $\mathrm{CP} 2^{\mathrm{M}}$ is true. The possible world above where Terry always gets shoelaces with his favorite untieable knot tied in them is obviously one where $C P 2^{\mathrm{M}}$ is true, since, in that world, were the trefoil knot isotopic to the unknot, Terry would have had a trefoil knot in the shoelace that he untied, and 'would' implies 'could'.

Let us consider the state of affairs versions of these modal explananda though.

$\mathrm{CP} 1^{\mathrm{M} *}$ : Were the trefoil knot isotopic to the unknot, the trefoil knot in Terry's shoelace could have been isotopic to the unknot.

$\mathrm{CP}^{\mathrm{M} *}$ : Were the trefoil knot isotopic to the unknot, Terry could have had a trefoil knot in his untieable shoelace.

$\mathrm{CP} 1^{\mathrm{M} *}$ is weakly necessarily true - every world where the trefoil knot in Terry's shoelace could not have been isotopic to the unknot is a world where $\mathrm{CP} 1^{\mathrm{M} *}$ is true. Thus, the fact that the trefoil knot in Terry's shoelace could not be isotopic to the unknot (FSA ${ }^{\mathrm{M}}$ ) has a DME, according to NOCA. CP2 $2^{\mathrm{M} *}$ is not weakly necessarily true - not every world where Terry could not have a trefoil knot in his untieable shoelace $\left(\mathrm{RSA}^{\mathrm{M}}\right)$ is a world where $\mathrm{CP} 2^{\mathrm{M} *}$ is true. For example, suppose Terry lives in a world where it is impossible to manufacture shoelaces with trefoil knots 
in them, because the only possible way to access the machines that manufacture shoelaces with trefoil knots in them requires the untying of a figure eight knot. In such a scenario, were the trefoil knot isotopic to the unknot, Terry still could not have had a trefoil knot in the shoelace that he untied, because no one could have untied the figure eight knot to gain access to the machines that manufacture trefoil knot shoelaces. According to NOCA, then, the fact that Terry could not have had a trefoil knot in his untieable shoelace does not have a DME. ${ }^{37}$

Let us get back to the original modal explananda now: that Terry could not have untied his shoelace that contains a trefoil knot (FEM) and that Terry could not have had a trefoil knot in the shoelace that he untied (REM). As we have seen, the fact that the trefoil knot in Terry's shoelace could not have been isotopic to the unknot (FSA ${ }^{\mathrm{M}}$ ) meets condition a) of NOCA. FSA ${ }^{\mathrm{M}}$ necessitates $\mathrm{FE}^{\mathrm{M}}$, so $\mathrm{FE}^{\mathrm{M}}$ meets condition b) of NOCA: every world where the trefoil knot in Terry's shoelace could not have been untieable is a world where Terry could not have untied it. FSA $^{\mathrm{M}}$ does not necessitate REM ${ }^{\mathrm{M}}$ : not every world where it is impossible for the trefoil knot in Terry's shoelace to be untieable is a world where it is impossible for Terry to have a trefoil knot in the shoelace that he untied. In FSA ${ }^{\mathrm{M}}$-worlds, Terry has a trefoil knot in his shoelace, and in $\mathrm{RE}^{\mathrm{M}}$-worlds, he does not. Thus, NOCA satisfies the directionality desideratum even for explicitly modal explananda. ${ }^{38}$

\footnotetext{
${ }^{37}$ I leave it to the reader to see that exactly similar modal counterpossibles hold true of the Königsberg's bridges, Mary's strawberries, and Patty's pendulum examples.

${ }^{38}$ I confess that my intuitions about these modal cases are not quite as strong as my intuitions about their nonmodal counterparts. I do not think it would be much of problem if it turned out that NOCA did not satisfy the directionality desideratum for these modal cases. For, that desideratum receives its plausibility from considering non-modal explananda, the directionality of which NOCA can account for, as we have seen. Note two things about the directionality desideratum of Craver and Povich ([2017]): first, it concerns only natural facts, and it is unclear whether modal facts are natural facts in their sense, though a closer look at this is beyond the scope of this paper. If modal facts are not natural facts, then the directionality desideratum arguably is not relevant for modal facts. Second, every one of their 'reversed' examples has a non-modal explanandum. Carl Craver ([personal communication]) speculates that the modal explananda are more mathematical (that is, closer to purely
} 
NOCA gives insight into how these modal facts can 'explain' non-modal facts. For example, we saw that FSA (that is, the trefoil knot in Terry's shoelace is distinct from the unknot) meets condition a) of NOCA. Assuming that FSAM is a natural fact, FSA meets condition b) as well, for it is necessitated by FSAM (that is, the trefoil knot in Terry's shoelace could not have been isotopic to the unknot), which itself meets condition a). But the non-modal fact's being necessitated by the modal fact is only distinctively mathematically explanatory because the modal fact itself weakly necessarily counterfactually depends only on a mathematical fact. $R^{M}$ necessitates RE, but RE does not have a DME because $R E^{M}$ does not meet condition a). Thus, if we focus on the necessitation relation and leave out the counterfactual dependence, we miss the real source of explanatory power of DME.

\section{Ontic Demystification}

I hope that I have shown that NOCA is a serious contender for an account of DME. Yet, there is a gap in my account. The proponent of NOCA should have something to say about the nature of the relation of counterfactual dependence involved in DMEs. Otherwise, although the account meets all the desiderata, it remains mysterious what the relation is between mathematical facts and the natural facts that they explain. For, counterfactual dependence is a relation that can hold for different reasons. $X$ could counterfactually depend on $y$, because, for example, $x$ and $y$ are identical (for example, were Mark Twain blonde, then Samuel Clemens would have been blonde), $y$ constitutes $x$ (for example, were Lumpl made of marble, then Goliath would have

mathematical facts) than their non-modal counterparts. If that is right, then this would help explain why we do not need a directionality desideratum in these cases, since we would have one (quasi-)mathematical fact explained by another. 
been made of marble ${ }^{39}$ ), or $y$ causes $x$ (for example, were the flagpole taller, then its shadow would have been longer). In a DME, when a natural fact counterfactually depends only on a mathematical fact, why does that dependence hold? Arguably, the mathematical fact is not identical to, does not constitute, and is not a cause of the natural fact.

There are several options for ontic relations that could ground the relevant counterpossibles, any of which the proponent of NOCA may choose. I will briefly canvas two: the grounding relation and a structuralist-inspired instantiation/realization relation.

First, perhaps in DMEs, when a natural fact counterfactually depends on a mathematical fact, it could be because the former is (at least partially) grounded in the latter. Furthermore, such grounding is asymmetric: the fact that Patty's double pendulum does (or does not) have at least four equilibrium configurations is grounded in the fact that a double pendulum's configuration space is (or is not) a torus with at least four stationary points, but not vice versa; Mary's failure to divide her twenty-three strawberries evenly among her three children is grounded in the fact that twenty-three is not divisible by three, but not vice versa. ${ }^{40}$ Therefore, grounding seems like a good candidate relation to explicate the relevant counterfactuals: the previous grounding claims are plausible, the grounding relation is asymmetric, and grounding is already widely recognized to be a relation that bears explanatory force. However, we would need to know more about the nature of this grounding relationship, and I do not here have the

\footnotetext{
${ }^{39}$ Goliath, of course, being a statue and Lumpl being the lump of clay that constitutes it (Gibbard [1975]).

${ }^{40}$ Whether this grounding claim is true depends on your philosophy of mathematics. A certain kind of empiricist/nominalist might reverse this and take natural facts to ground mathematical facts. For that reason, they are unlikely to think that putative DMEs are explanatory in the first place. The ontic story suggested here assumes some form of mathematical realism or Platonism. I am currently working on making my account nominalistically acceptable. Cryptically, the thought is to be trivialist (Rayo [2009], [2013]) about the mathematics and interpret the instantiation relation as a semantic, rather than ontic, relation. Note that Rayo does not consider trivialism a form of nominalism, but it seems to me that it can easily be put to nominalist uses (see, for example, (Heil [2012])).
} 
space to wade into that extensive and controversial literature (see Correia and Schnieder [2012]). Similarly, one might appeal to the in virtue of relation: the natural fact obtains in virtue of the fact that the mathematical fact does, but not vice versa. Again, this may be plausible but not very illuminating; it seems like a redescription of the grounding relation we want illuminated.

When thinking about what the nature of the relation of counterfactual dependence could be, it may be helpful to think about the nature of the relata. For, different accounts of the ontology of mathematical facts may suggest certain relations. (I assume here that natural facts are unproblematic, but I will not assume any particular account. Note though, that all the narrowed, natural facts that admit of DME that we have considered all possess a certain kind of de re or weak necessity - in every possible world where Patty's double pendulum exists, Patty's double pendulum has at least four equilibrium configurations, for instance.) For example, on one prominent structuralist ontology, where mathematical objects are abstract structures or patterns, 'the relationship between mathematics and material reality is, in part, a special case of the ancient problem of the instantiation of universals. Mathematics is to reality as universal is to instantiated particular' (Shapiro [1997], p. 248). The second option, then, is that in a DME, when a natural fact counterfactually depends only on, and is explained by, a mathematical fact, it is because the former is an instantiation, or perhaps a realization (Huneman [2010]), of the latter but not vice versa. This is especially plausible for DMEs of what I called earlier 'states of affairs explananda'. The natural fact instantiates/realizes the mathematical objects and properties/relations that compose the mathematical fact. Patty's double pendulum (the concrete object) is an instantiation or realization of the double pendulum (the abstract, 
mathematical object) and, according to the mathematical fact, the double pendulum (the abstract, mathematical object), possesses the property of having at least four equilibrium configurations, so any instantiation of that mathematical object, such as Patty's double pendulum, will also instantiate the property of having four equilibrium configurations. The double pendulum (the abstract, mathematical object) is not an instantiation/realization of Patty's double pendulum (the concrete object), so instantiation is asymmetric, and this asymmetry can account for any explanatory asymmetry.

When we are dealing for DMEs for event explananda, the instantiation/realization relation combines with necessitation and componency relations. The (natural) fact that the (concrete) trefoil knot in Terry's shoelace is distinct from the unknot is an instantiation/realization of the (mathematical) fact that the (abstract) trefoil knot is distinct from the unknot. This natural fact is a component of and necessitates the event that Terry failed to untie the trefoil knot in his shoelace. ${ }^{41}$ Another way to say the same thing: the mathematical fact is instantiated in the explanandum-event and that instantiatied fact necessitates the explanandum-event.

\footnotetext{
${ }^{41}$ Going the instantiation route would make my account similar to Lyon's ([2012]) program account of DME (see also Pincock's ([2015]) related account of abstract explanation). Lyon ([2012]), following Jackson and Pettit (1990), takes a program explanation to be 'one that cites a property or entity that, although not causally efficacious, ensures the instantiation of a causally efficacious property or entity that is an actual cause of the explanandum' ( $p$. 566). In general, I am sympathetic to his (and Pincock's) account, and I am happy to see my account as of a piece with his, though a detailed comparison of our accounts is beyond the scope of the current paper. Thanks to an anonymous referee for pointing this out. One important difference between NOCA and the program account is that, on NOCA, the instantiated property needs to do more than cause the explanandum. To meet condition b), the instantiated property must be (instantiated in an object that is) a component of and necessitate the explanandum to count as a DME. Instantiated properties cause all kinds of things that do not thereby have DMEs. For example, the instantiation of network structure $\mathrm{P}$ in Königsberg's bridges ensures that causally efficacious properties are on the scene to cause a certain pattern of air flow, a rise in tourism, boats to crash, Marta to smile, and so on, none of which are distinctively mathematically explained by network structure P. Thus, NOCA is superior to Lyon's program account on this count.
} 
Before moving on to objections, I should like to clarify more the relation between the ontic aspect of NOCA and the counterfactual aspect. Relations of counterfactual dependence hold in virtue of relations of ontic dependence. Like supervenience, counterfactual dependence is a modal concept. Supervenience could hold in virtue of the holding of different relations of ontic dependence, including, among others, identity, constitution, and causal sufficiency (Heil [2003], p. 67). My emphasis on counterfactual dependence is essential though, because it is only with information about counterfactual dependence that one can answer w-questions (Bokulich [2011]; Rice [2015]; Saatsi and Pexton [2013]; Woodward [2003]). Thus, counterfactual dependence is what unites different forms of ontic dependence (causation, constitution, grounding, etc.) and the different forms of explanation that describe them. On the general view of explanation that I favor, the Generalized Ontic Conception (Povich [2018]), explanation involves exhibiting ontic relations that support counterfactuals (see also Pincock [2015]). Their ability to support counterfactuals is what unites these ontic relations as explanatory relations. I agree with Woodward ([2003], pp. 210-20), who holds that it is in virtue of conveying counterfactual information that causal relations are explanatory. Perhaps one can view NOCA as showing what kinds of counterfactual an ontic relation (for example, instantiation) needs to support, if it is to capture all of our intuitive judgments about DME.

\section{Objections to NOCA}

I have argued that an ontic variety of counterfactualism, NOCA, can satisfy the three desiderata for DMEs. I now consider some objections to my proposal.

First, consider the fact that, according to NOCA, the indivisibility of twenty-three by three explains why Mary failed to divide evenly twenty-three strawberries among her three 
children, since, had twenty-three been divisible by three, then Mary would have succeeded.

Arguably, had twenty-six been divisible by three, then twenty-three would have been divisible

by three. Does this mean that Mary's failure counterfactually depends on the indivisibility of

twenty-six by three? If so, then this is a counterexample to NOCA, since, arguably, the

indivisibility of twenty-six by three does not explain Mary's failure, although the latter

counterfactually depends on the former.

As stated, this objection commits the counterfactual fallacy of transitivity (Lewis [1973],

p. 32) $)^{42}$. Transitive inferences are valid for material conditionals but not counterfactual

conditionals. It could be true that had twenty-three been divisible evenly by three, then Mary

would have succeeded and that had twenty-six been divisible evenly by three, then twenty-

three would have been, but it does not follow from those truths that had twenty-six been

divisible evenly by three, then Mary would have succeeded.

Lewis ([1973], p. 33) gives the following counterexample, due to Stalnaker, to this

inference pattern:

\footnotetext{
${ }^{42}$ As a careful reviewer notes, the objection can be reformulating without going through a chain of counterfactuals, thus escaping the transitivity charge. One could use the indicative conditional that if twenty-six is divisible by three, then twenty-three is divisible by three. If we hold this indicative conditional fixed when we go to a world in which we 'twiddle' twenty-six, we should get a corresponding change to twenty-three, making the problematic counterfactual (that is, 'had twenty-six been divisible by three, Mary would have succeeded') true. Although this escapes the transitivity charge, it still runs afoul of the surgical strike rule for twiddling (see below). Now, you might reasonably worry about how we can twiddle twenty-six and hold everything fixed, including twenty-three, without generating further contradictions. I do not think this is too much of a worry though. As Baron et al. ([2017], p. 9) point out, this should not be any more worrisome than it is when we evaluate standard counterfactuals:
}

But we do not need to resolve all the looming contradictions. We just need to resolve those relevant to assessing the counterfactual at hand. After all, that's all we do in the Suzy and the rock case. We do not go all the way back to the big bang or even to Suzie's birth in order to achieve consistency. We iron out the immediate inconsistencies and leave it there. But somewhere in the background there will be further inconsistencies looming. Suzy moved her arm in a throwing motion, yet the rock did not move? She willed her arm to move, but it didn't? We simply set these problems aside because they are not relevant to the assessment of the counterfactual of interest. 
P1: If J. Edgar Hoover had been born a Russian, then he would have been a Communist.

P2: If he had been a Communist, then he would have been a traitor.

C: If he had been born a Russian, then he would have been a traitor.

However, Lewis is careful to note that transitivity fails when the antecedent of the first premise is more far-fetched than the antecedent of the second, and that does not seem true of the inference in the objection. And, of course, that the inference is invalid does not show that its conclusion (that is, that had twenty-six been divisible by three, Mary would have succeeded) is false. However, I do not see why we should believe it is true. At the very least, Baron, Colyvan, and Ripley ([2017]) show how to evaluate such a countermathematical in such a way that it is false. Evaluating countermathematicals requires decisions about what and how much mathematics to hold fixed (just as evaluating an ordinary counterfactual requires decisions about what and how many empirical facts to hold fixed). Consider their ([2017], p. 7) remarks on 'twiddling' the number thirteen by giving it the factors two and six:

We should not go too far, however; we still want to hold fixed as much as we can with respect to the natural numbers. What we're ultimately interested in, recall, are the ramifications of twiddling 13 . We are not interested in the ramifications of twiddling any other number. In other words, we want to be able to carry out a 'surgical strike' on 13 that enables us to gauge the consequences of altering this number for physical reality in as much isolation as possible from alterations to anything else within mathematics.

Baron et al. ([2017], pp. 7-9) show how to perform such a surgical strike by changing the multiplication function so that $2 \times 6=13$. Similarly, we want a 'surgical strike' on twenty-six not to have consequences for twenty-three and for Mary's success or failure. Thus, Baron et al.'s procedure for evaluating countermathematicals allows me to say that it is false that, had twenty-six been divisible by three, then Mary would have succeeded. 
Next, according to NOCA, the fact that network structure P does not permit an Eulerian walk explains why Marta failed to make an Eulerian walk across Königsberg's bridges (which we presuppose have network structure P). Intuitively, Euler's general theorem that a network permits an Eulerian walk if and only if exactly zero or two of the nodes has an odd number of edges also explains why Marta failed to make an Eulerian walk across Königsberg's bridges (and, similarly, explains the state of affairs version of this explanandum, that Königsberg's bridges, which have network structure $\mathrm{P}$, do not permit an Eulerian walk). However, arguably there are worlds where it is false that had Euler's general theorem been false, then Marta would have made an Eulerian walk across Königsberg's bridges (or Königsberg's bridges, which have network structure $\mathrm{P}$, would have permitted an Eulerian walk). Thus, we have a case of DME that does not meet either condition of NOCA.

I think I am forced to accept the counterintuitive consequence that Euler's general theorem does not explain why Marta failed to make an Eulerian walk across Königsberg's bridges (or why Königsberg's bridges, which have network structure $P$, do not permit an Eulerian walk) ${ }^{43}$. For, although from Euler's theorem it follows that Königsberg's bridges, which have network structure $\mathrm{P}$, do not permit an Eulerian walk, had Euler's theorem been false, it might still have been the case that Königsberg's bridges, which have network structure $P$, do not permit an Eulerian walk (for example, in a world where Euler's theorem is false because its sufficiency component is false, but its necessity component is still true). (Nor is the explanandum-fact an instantiation of the explanans-fact.) Euler's theorem necessitates the fact

\footnotetext{
${ }^{43}$ Of course, as a last resort, one could restrict NOCA to giving sufficient conditions for explanation, rather than necessary and sufficient conditions.
} 
that Königsberg's bridges, which have network structure $\mathrm{P}$, do not permit an Eulerian walk, but the latter fact does not weakly necessarily counterfactually depend on the former. This is one of those misleading cases of necessitation without counterfactual dependence.

This appears to be a general consequence of NOCA, and arguably of any counterfactual theory of explanation, regarding the limited explanatory status of facts (that is, positive facts see below) about material equivalence. For example, from the fact that being an eligible, unmarried man is necessary and sufficient for being a bachelor, it follows (that is, necessitates) that Martha, a woman, is not a bachelor. However, were being an eligible, unmarried man not necessary and sufficient for being a bachelor, it would not necessarily follow that Martha would have been a bachelor.

Let us return to Königsberg's bridges and Euler's theorem. Consider this counterpossible: Had Euler's general theorem been false, then Königsberg's bridges, which permit an Eulerian walk, would have had network structure P. This is not weakly necessary for a similar reason that the previous counterpossible is not: had Euler's theorem been false, it might still have been the case that Königsberg's bridges, which permit an Eulerian walk, would not have had network structure P (for example, in a world where Euler's theorem is false because its necessity component is false, but its sufficiency component is still true). Therefore, Euler's theorem does not distinctively mathematically explain RSA' either.

Let us focus on the sufficiency claim, then. Surely, this counterpossible is weakly necessary: Had permitting an Eulerian walk been sufficient for having network structure $P$, then Königsberg's bridges, which permit an Eulerian walk (or across which Marta made such a walk), would have had network structure P. It seems that the fact that it is not the case that 
permitting an Eulerian walk is sufficient for having network structure P distinctively mathematically explains why Königsberg's bridges, which permit an Eulerian walk (or across which Marta made such a walk), do not have network structure P.

Here is where the ontic story can be helpful. If, for example, the instantiation relation is the ontic relation that 'grounds' the relevant, explanatory counterfactuals, then it can be used to exclude otherwise problematic counterfactuals that have no such grounding. The same thing is true of other ontic relations and the kinds of explanation they support. For example, there may be counterfactual dependence between one fact (or event or whatever) and another, but if that dependence does not hold in virtue of a causal relation between them, then the one fact does not causally explain the other. In this objection, the putative explanans-fact is a mathematical theorem, and a theorem, let alone a negative one, cannot be instantiated (at least the way a mathematical fact composed of mathematical objects and mathematical properties/relations - call these ' $m$-facts' - can, which is the way appealed to in the instantiation story above). This may be easier to see if we consider the logical structure of theorems, in the relevant sense, and m-facts. A theorem, in the relevant sense, is a universal generalization with a variable that ranges over mathematical objects. No object itself is mentioned. The putatively explanatory theorem at issue says something like: it is not the case that for all $\mathrm{x}$, if $\mathrm{x}$ permits an Eulerian walk, then $\mathrm{x}$ has network structure $\mathrm{P}$ (where $\mathrm{x}$ ranges over mathematical objects). The fact that Königsberg's bridges, which permit an Eulerian walk (or across which Marta made such a walk), do not have network structure $P$ is not an instantiation of this negative universal generalization. 
This last point seems right, but did we reach it merely by a trick of logical notation or of linguistic representation? We can remove the negative universal generalization altogether by simply changing our property-terms and object-terms like this: the Eulerian network does not have network structure $\mathrm{P}$ (where 'the Eulerian network' refers to the network that permits an Eulerian walk). This seems to express the same fact expressed by the negative universal generalization and it distinctively mathematically explains why Königsberg's bridges, which permit an Eulerian walk (or across which Marta made such a walk), do not have network structure P. For, it is weakly necessary that, had the Eulerian network had network structure $\mathrm{P}$, then Königsberg's bridges, which permit an Eulerian walk (or across which Marta made such a walk), would have had network structure P. Furthermore, the explanandum-fact instantiates the explanans-fact: Königsberg's bridges are an instantiation of the mathematical object the Eulerian network and they also instantiate the mathematical property not having network structure $P$.

The trouble here is that 'the Eulerian network' is not a mathematical object. It is actually many different networks made to fall under a gerrymandered singular term. The objector is the one who has made the linguistic trick. We can use a name in the logical calculus, say ' $t$,' to denote the mathematical object, the trefoil knot, and a predicate, $D$, to denote the property of being distinct from the unkot (or the set of objects to which the predicate applies). Thus, Dt expresses the proposition that the trefoil knot is distinct from the unknot. However, the name can be 'converted' into a predicate, T, denoting the property of being a trefoil knot (or the set of objects to which the predicate applies). A proposition similar to the one expressed by Dt can then be expressed by 'for all $x$, if Tx, then Dx,' ' $x$ ' ranging over mathematical objects. But this 
only works for an object and the property of being that object. One cannot sensibly turn the predicate 'is red' into the name of an object. 'Eulerian network' does not denote a mathematical object. Being an Eulerian network is a property had by many mathematical objects. This is true even if the property in question is possessed by an object essentially. They are still very different kinds of thing. Excluding some reversals, then, requires NOCA firmly to commit to the idea that some mathematical objects exist, and others do not (and cannot). This means that NOCA is committed to a privileged mathematical ontology - not just anything goes. Now, Povich ([under review]) criticizes Lange ([forthcoming]) for assuming a privileged ontology because, to avoid Craver and Povich's ([2017]) reversals, Lange must exclude the reality of certain objects (for example, knots whose isotopy to the unknot is constitutive of them). I must similarly accept a privileged ontology, so that 'the Eulerian network' is excluded as a mathematical object that can be instantiated. Accepting a privileged ontology is arguably a bigger problem for Lange ([2013], [forthcoming]), though, since his account has a psychological component: one of the empirical explanans-facts in a DME must be understood in the why question's context to be constitutive of the physical task or arrangement at issue. Lange has placed no restrictions on what can be understood to be constitutive of what in a context. If both require a privileged ontology to escape reversals, why prefer NOCA over Lange's account? The reason lies in the overall picture of explanation NOCA provides. Only NOCA delivers a unified picture of explanation, where DME and causal-mechanical explanation are species of a common genus, united by ontically-backed counterfactual dependence.

Finally, there is a worry about the nature of the explananda of DMEs on NOCA. The worry is that since all of the explanandum-statements use mathematical vocabulary, perhaps 
ineliminably, the putative DMEs are not mathematical explanations of natural facts, at least not of purely natural facts ${ }^{44}$. Bangu ([2008]) presses this worry to undermine arguments for mathematical realism that rely on DMEs. Since DMEs assume mathematical realism, according to Bangu, they cannot be used in an argument for mathematical realism. However, I am not using DMEs to argue for mathematical realism ${ }^{45}$, so Bangu's argument does not apply. A worry would remain if there were any reason to suppose that there cannot be DMEs of mixed naturalmathematical facts (that is, facts composed of both natural and mathematical objects and properties/relations), but this is not the case. First, the move from 'mixed natural-mathematical statement' to 'mixed natural-mathematical fact' is controversial. Even if the explanandumstatement employs both natural and mathematical terms, that need not imply that it refers to a mixed natural-mathematical fact. It is possible that the truthmakers for mixed naturalmathematical statements are purely natural facts, and this does not require any kind of paraphrasing of mathematical terms out of mixed natural-mathematical statements. For example, it is possible that the natural facts that compose our solar system make true the statement, 'The number of planets in our solar system is even' ${ }^{46}$ Second, all the philosophical

\footnotetext{
${ }^{44}$ I thank an anonymous referee for pushing me here and bringing this discussion between Bangu and Baker to my attention.

${ }^{45}$ Though I think an argument from the results of this paper to mathematical realism is available. To establish mathematical realism, according to Bueno, 'The use of mathematics, perhaps in conjunction with some other factors, needs to be ultimately responsible for the explanation in question. After all, if something else other than the mathematics is providing the explanation, it is unclear why any ontological weight should be given to the relevant mathematics' ([2012], p. 968; original emphasis). Clearly in the narrowed examples I have been considering, there is nothing other than the mathematics to provide the explanation. Furthermore, the mathematics in these examples does not appear to be playing a merely indexing or representational role (compare (Melia [2000]; Daly and Langford [2009])).

${ }^{46}$ A full exploration of this idea would take me too far afield. See, for example, Cameron ([2010]), Dyke ([2012]), and Heil ([2003]). Rayo ([2009], [2013]) and Thomasson ([2014]) are also relevant here, though they would adamantly resist my 'truthmaker' talk and, likely, NOCA.
} 
work that DMEs are supposed to do (in philosophy of explanation, ${ }^{47}$ at least) can still be done if their explananda are mixed natural-mathematical facts. When put to work in philosophy of explanation, DMEs are supposed to challenge the causal, or more broadly ontic, consensus, and they can still do that if their explananda are mixed natural-mathematical facts. This is because causal/ontic explanations can also be given for mixed natural-mathematical facts, so DMEs can compete with causal/ontic explanations ${ }^{48}$. The reason that no one thinks mathematical explanations of purely mathematical facts challenge the causal/ontic consensus is that purely mathematical facts were never meant to fall under the purview of causal/ontic accounts of explanation. Mixed natural-mathematical facts ${ }^{49}$ do fall under their purview. Obviously DMEs could not do this philosophical work if their explananda were purely mathematical, but that is not that case. None of the explananda in the examples throughout this paper are composed only of mathematical objects and properties/relations.

Here is one more argument that the narrow explananda in all my examples are natural facts (or at least natural enough to fall under the purview of the causal/ontic consensus). These narrow explananda are the result of combining the original explananda of prominent cases with the non-mathematical facts that figure in their explanantia. Now, everyone to this debate agrees that the original explananda and the non-mathematical explanantia are natural facts (or at least natural enough to fall under the purview of the causal/ontic consensus). It is not

\footnotetext{
${ }^{47}$ Which is my concern here. See Baker ([2009]) for a reply to Bangu ([2008]) that argues that DMEs can still do philosophical work for metaphysics of mathematics if their explananda are mixed natural-mathematical facts. ${ }^{48}$ See, among many others, Colyvan ([2010]), Lange ([2013]), and Lyon ([2012]), who discuss the ways in which DMEs and causal explanations for mixed natural-mathematical facts compete.

${ }^{49}$ At least those that are not also explicitly modal. Perhaps facts such as that necessarily $p$, where $p$ is a natural fact or a mixed natural-mathematical fact, were never intended to fall under the purview of causal/ontic accounts.
} 
plausible that combining two natural facts results in a purely mathematical fact. Thus, my narrow explananda are natural facts.

\section{Conclusion}

Let us take stock. I argued that any philosophical account of distinctively mathematical explanation should satisfy three desiderata: it should account for the modal import of some distinctively mathematical explanations; it should distinguish uses of mathematics in explanation that are distinctively mathematical from those that are not (Baron [2016]); and it should also account for the directionality of distinctively mathematical explanations (Craver and Povich [2017]). I argued that Baron's ([forthcoming]) and Lange's ([2013]) accounts of DME do not meet these desiderata. Then, I showed how a ontically-backed counterfactual account of DME, the Narrow Ontic Counterfactual Account (NOCA), can meet the desiderata.

However, there is a gap in NOCA: we need an account of the relation between mathematical facts and natural facts (the demystification challenge). I briefly canvassed two asymmetric ontic relations that might hold between mathematical and natural facts: the grounding relation and the instantiation/realization relation.

By unifying ontic and modal explanations, NOCA shows the weakness of that distinction. In a suggestive footnote, Craver and Povich ([2017], p. 37) conjecture that if a counterfactual account of distinctively mathematical explanation is workable, that would go some way toward dissolving the distinction between modal and ontic conceptions of scientific explanation. I think they are right, and NOCA shows how. Lange ([2013], [2016]) portrays DME not only as a challenge to the causal hegemony, but as a challenge to any ontic conception of scientific explanation, that is, any conception of explanation on which the only legitimate explanantia are 
ontic, such as causes, mechanisms, natural regularities, and so on ${ }^{50}$. Some DMEs, Lange argued, are accommodable only by a modal, rather than an ontic, conception of explanation. We have already seen why this is supposed to be the case: because of their strong modal import.

However, NOCA is a monistic account of explanation. It says that all explanations follow a single pattern: they all exhibit relations of counterfactual dependence that hold in virtue of some ontic relation between explanans and explanandum. NOCA thus portrays DME as one element in an intuitive typology of kinds of explanation that are individuated by the ontic relation in virtue of which the relation of counterfactual dependence holds between explanans and explanandum. When the relation of counterfactual dependence holds in virtue of a causal relation between explanans and explanandum, we have a causal explanation. When the relation of counterfactual dependence holds in virtue of a constitutive/mechanistic relation between explanans and explanandum, we have a constitutive/mechanistic explanation. When the relation of counterfactual dependence holds in virtue of a relation like instantiation (sometimes together with componency and necessitation) between mathematical explanans and natural explanandum, we have a distinctively mathematical explanation. NOCA thus unifies causal and non-causal, ontic and modal.

While there are important differences between DMEs and non-DMEs, ultimately, I think, the distinction between ontic and modal conceptions of explanation is not a useful one ${ }^{51}$. There is no need to distinguish between ontic and modal conceptions of explanation for the same

\footnotetext{
50 On the ontic conception, see Craver ([2014]), Povich ([2018]), and Salmon ([1989]).

${ }^{51}$ Of course, there is also the so-called epistemic conception of explanation (Salmon [1989]). To the extent that this conception is committed to the idea that explanations are deductive arguments, it is unworkable for DME, as we have seen in Baron's account.
} 
reason that there is no need to distinguish between causal and mechanistic conceptions, important differences between causal and mechanistic explanations there may be. All explanations - ontic and modal, causal and non-causal - work in the same basic way and inherit their explanatory power from the same basic source: ontically-backed counterfactual dependence.

\section{Acknowledgements}

Thanks to Carl Craver, Marc Lange, Joseph McCaffrey, two anonymous referees, and audience members of the poster session of the 26th Biennial Meeting of the Philosophy of Science Association for invaluable feedback.

Philosophy

Washington University in St. Louis

St. Louis, MO, USA

mapovich@wustl.edu

\section{References}

Baker, A. [2005]: 'Are There Genuine Mathematical Explanations of Physical Phenomena?', Mind, 114, pp. 223-38.

Baker, A. [2009]: 'Mathematical Explanations in Science', British Journal for the Philosophy of Science, 60, pp. 611-33.

Baker, A. [2012]: 'Science-driven Mathematical Explanation', Mind, 121, pp. 243-67.

Bangu, S. [2008]: 'Inference to the Best Explanation and Mathematical Realism', Synthese, 160, pp. 13-20. 
Baron, S. [2016]: 'Explaining Mathematical Explanation', The Philosophical Quarterly, 66, pp. 458-80.

Baron, S. [Forthcoming]: 'Mathematical Explanation by Law', British Journal for the Philosophy of Science.

Baron, S., Colyvan, M. and Ripley, D. [2017]: 'How Mathematics Makes a Difference', Philosophers' Imprint, 17, pp. 1-29.

Bokulich, A. [2011]: 'How Scientific Models Can Explain', Synthese, 180, pp. 33-45.

Bromberger, S. [1966]: 'Why Questions', in R. G. Colodney (ed.), Mind and Cosmos, Pittsburgh, PA: University of Pittsburgh Press, pp. 86-111.

Bueno, O. [2012]: 'An Easy Road to Nominalism', Mind, 121, pp. 967-82.

Cameron, R. [2010]: 'How to Have a Radically Minimal Ontology', Philosophical Studies, 151, pp. 249-64.

Colyvan, M. [1998]: 'Can the Eleatic Principle Be Justified?', Canadian Journal of Philosophy, 28, pp. 313-35.

Colyvan, M. [2010]: 'There is No Easy Road to Nominalism', Mind, 119, pp. 285-306.

Correia, F., and Schnieder, B. [2012]: Metaphysical Grounding: Understanding the Structure of Reality, Cambridge: Cambridge University Press.

Craver, C. F. [2014]: 'The Ontic Account of Scientific Explanation', in M. Kaiser, O. Scholz, D. Plenge and A. Hüttemann (eds), Explanation in the Special Sciences: The Case of Biology and History, New York: Springer, pp. 27-54.

Craver, C. F. and Povich, M. [2017]: 'The Directionality of Distinctively Mathematical Explanations', Studies in History and Philosophy of Science Part A, 63, pp. 31-8. 
Daly, C. and Langford, S. [2009]: 'Mathematical Explanation and Indispensability Arguments', The Philosophical Quarterly, 59, pp. 641-58.

Dyke, H. [2012]: Metaphysics and the Representational Fallacy, Routledge.

Gibbard, A. [1975]: 'Contingent Identity', Journal of Philosophical Logic, 4, pp. 187-221.

Heil, J. [2003]: From an Ontological Point of View, Oxford: Oxford University Press.

Heil, J. [2012]: The Universe as We Find It, Oxford: Oxford University Press.

Hempel, C. [1965]: Aspects of Scientific Explanation and Other essays in the Philosophy of Science, New York, NY: The Free Press.

Huneman, P. [2010]: 'Topological Explanations and Robustness in Biological Sciences', Synthese, 177, pp. 213-45.

Jackson, F. and Pettit, P. [1990]: 'Program Explanation: A General Perspective’, Analysis, 50, pp. 107-17.

Kripke, S. [1971]: 'Identity and Necessity', in M.K. Munitz (ed), Identity and Individuation, New York: New York University Press, pp. 135-64.

Lange, M. [2013]: 'What Makes a Scientific Explanation Distinctively Mathematical?', British Journal for Philosophy of Science, 64, pp. 485-511.

Lange, M. [2016]: Because Without Cause: Non-Causal Explanations in Science and Mathematics. Oxford: Oxford University Press.

Lange, M. [Forthcoming]: 'A Reply to Craver and Povich on the Directionality of Distinctively Mathematical Explanations', Studies in History and Philosophy of Science Part A. 
Leng, M. [2005]: 'Mathematical Explanation', in C. Cellucci and D. Gillies (eds), Mathematical Reasoning, Heuristics, and the Development of Mathematics, London: King's College Publications, pp. 167-89.

Lewis, D. [1973]: Counterfactuals. Oxford: Blackwell Publishers.

Lewis, D. [1983]: 'New Work for a Theory of Universals', Australasian Journal of Philosophy, 61, pp. 343-77.

Lewis, D. [1986]: 'Causal Explanation', in D. Lewis (ed), Philosophical Papers, Vol. 2, New York: Oxford University Press, pp. 214-40.

Lyon, A. [2012]: 'Mathematical Explanations of Empirical Facts, and Mathematical Realism', Australasian Journal of Philosophy, 90, pp. 559-78.

Mancosu, P. [2008]: 'Mathematical Explanation: Why it Matters', in P. Mancosu (ed), The Philosophy of Mathematical Practice, Oxford: Oxford University Press, pp. 134-50.

Melia, J. [2000]: 'Weaseling Away the Indispensability Argument', Mind, 109, pp. 455-80.

Pincock, C. [2015]: 'Abstract Explanations in Science', British Journal for the Philosophy of Science, 66, pp. 857-82.

Povich, M. [2018]: 'Minimal Models and the Generalized Ontic Conception of Scientific Explanation', British Journal for the Philosophy of Science, 69, pp. 117-37.

Povich, M. [Under review]: 'Modality and Constitution: A Reply to Lange'.

Rayo, A. [2009]: 'Toward a Trivialist Account of Mathematics', in O. Bueno and $\varnothing$. Linnebo (eds), New Waves in Philosophy of Mathematics, London: Palgrave Macmillan, pp. 239-60.

Rayo, A. [2013]: The Construction of Logical Space, Oxford: Oxford University Press. 
Reutlinger, A. [2016]: 'Is There A Monist Theory of Causal and Noncausal Explanations? The Counterfactual Theory of Scientific Explanation', Philosophy of Science, 83, pp. 733-45.

Reutlinger, A. [2017]: 'Does the Counterfactual Theory of Explanation Apply to Non-causal Explanations in Metaphysics?', European Journal for Philosophy of Science, 7, pp. 23956.

Rice, C. [2015]: 'Moving Beyond Causes: Optimality Models and Scientific Explanation', Noûs, 49, pp. 589-615.

Saatsi, J. and Pexton, M. [2013]: 'Reassessing Woodward's Account of Explanation: Regularities, Counterfactuals, and Noncausal Explanations', Philosophy of Science, 80, pp. 613-24.

Salmon, W. C. [1984]: Scientific Explanation and the Causal Structure of the World, Princeton, NJ: Princeton University Press.

Salmon, W. C. [1989]: 'Four Decades of Scientific Explanation', in W. Salmon and P. Kitcher (eds), Scientific Explanation, Minneapolis, MN: University of Minnesota Press, pp. 3219.

Schaffer, J. [2010]: 'The Least Discerning and Most Promiscuous Truthmaker', The Philosophical Quarterly, 60, pp. 307-24.

Shapiro, S. [1997]: Philosophy of Mathematics: Structure and Ontology, Oxford: Oxford University Press.

Skow, B. [2016]: Reasons Why, Oxford: Oxford University Press.

Steiner, M. [1978]: 'Mathematics, Explanation, and Scientific Knowledge', Noûs, 12, pp. 17-28.

Strevens, M. [2008]: Depth: An Account of Scientific Explanation, Cambridge, MA: Harvard University Press. 
Thomasson, A. L. [2014]: Ontology Made Easy, Oxford: Oxford University Press.

Woodward, J. [2003]: Making Things Happen: A Theory of Causal Explanation, Oxford: Oxford University Press. 